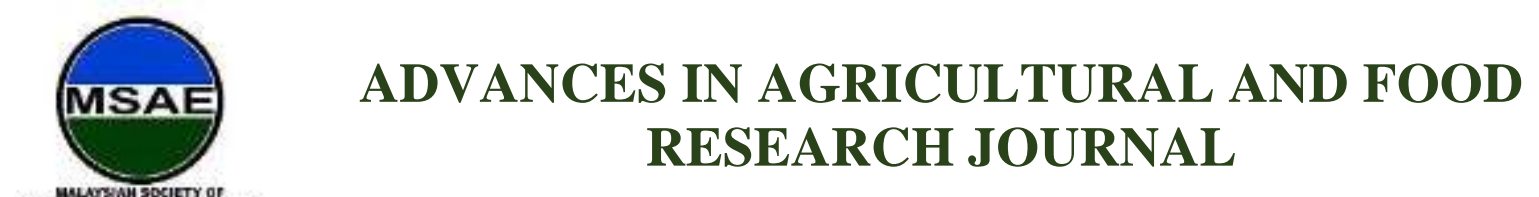

Original Research Article

\title{
Optimization of Design and Operational Parameters of a Soil-Dispensing Machine for Preparing Seedling Tray
}

\author{
Hafidha Azmon ${ }^{1 *}$, Mohd Fazly Mail ${ }^{1}$, Mohd Shukry Hassan Basri ${ }^{2}$, Norahshekin Abdul Rahman ${ }^{1}$, Siti Ashah \\ Ab Rahim ${ }^{1}$ \\ ${ }^{1}$ Farm Mechanization Program, Engineering Research Centre, Malaysian Agricultural Research and \\ Development Institute (MARDI), Serdang Selangor, fazlym@ mardi.gov.my \\ ${ }^{2}$ Smart and Precision Farming Program, Engineering Research Centre, Malaysian Agricultural Research and \\ Development Institute (MARDI), Serdang Selangor, shukry@ mardi.gov.my \\ *Corresponding author: Hafidha Azmon, Farm Mechanization Program, Engineering Research Centre, \\ Malaysian Agricultural Research and Development Institute (MARDI), Serdang Selangor, Malaysia; \\ hafidha.mardi@1govuc.gov.my
}

\begin{abstract}
The conventional method of soil filling into nursery trays before seeding is known to be the most inexpensive approach prior to planting vegetables. However, this activity is very labourious and time-consuming if the operation is meant for high volume seeding. This study is done to develop soil-dispensing machine, evaluate its performance and to compare with traditional practice of soil filling into the nursery tray. The optimization of each parameter is also evaluated to obtain the exact volume of soil to fill the nursery tray to the fullest. A low-cost soil dispensing machine is developed in MARDI and it is using locally materials available in the market. The structure of the machine is fabricated using mild-steel and stainless-steel at the less cost. The machine consists of a conveyor, nursery tray holder, soil dispenser, scrapper, soil compactor, wiper motors, gears, microcontroller and sensors. There are three factors with two levels involve in this test; hopper angle, conveyor speed and auger speed. The hopper angles are evaluated at $45^{\circ}$ and $65^{\circ}$ while conveyor speeds are tested at $19 \mathrm{~cm} / \mathrm{s}$ and $21 \mathrm{~cm} / \mathrm{s}$. The minimum and maximum speed of auger selected is $3.5 \mathrm{~cm} / \mathrm{s}$ and $4.5 \mathrm{~cm} / \mathrm{s}$, respectively. Manual filling of soil into seedling tray was compared with filling soil using semi-automatic operated soil-dispenser. The results indicated that the model is significant with $p$-value $<0.0001$. Conveyor speed, auger speed and hopper angle were significant on the volume of soil dispensed with both speeds shows a $p$-value $<0.0001$, while hopper angle shows $p$-value equal to 0.00112 . The combination of both speeds greatly affected the response with $p$-value $<0.0001$. There is no interaction between each speed and the hopper angle. From the optimization analysis, the operating conveyor speed, auger speed and angle of hopper should be set at $19.0 \mathrm{~cm} / \mathrm{s}, 4.5 \mathrm{~cm} / \mathrm{s}$ and $65^{\circ}$ to discharge $2912 \mathrm{~cm}^{3}$ soil. In order to dispense $1190 \mathrm{~cm}^{3}$ of soil, conveyor speed, auger speed and hopper angle should be set at $21 \mathrm{~cm} / \mathrm{s}, 4.3 \mathrm{~cm} / \mathrm{s}$ and $50^{\circ}$. The result indicated that the machine can complete the seeding and soil filling process within 1 min per tray, while manual process took five minutes to complete the whole seeding process.
\end{abstract}

Keywords: nursery tray; soil dispenser; soil compactor; seed dispenser 
Received: $27^{\text {th }}$ October 2020

Citation: Azmon H, Mail MF, Basri MSH, et al. (2020). Optimization of design and operational parameters of a soil-dispensing machine for Accepted: $27^{\text {th }}$ November 2020 seedling tray. Adv Agri Food Res J 2020; 1(2):

Published Online: $4^{\text {th }}$ December 2020 a0000143. https://doi.org/10.36877/aafrj. a0000143

\section{Introduction}

Vegetables are rich in vitamins and comparatively cheaper source of food. They provide all the important nutrients such as proteins, fats, starch, minerals and vitamin. Thus, their daily consumption is necessary for a balanced diet. Nowadays, increasing awareness in Malaysia citizen on healthy lifestyle has boost the demand for vegetable in Malaysia. Malaysia has produced 1.06 million tons of vegetables in 2018 which is $5.6 \%$ higher than a year before (DOA, 2019). Pahang is the biggest vegetable producing state in Malaysia with 18,296 ha grown area followed by Johor with 17,171 ha (DOA, 2019). The statistic shows that vegetable production is projected to increase annually by $1.6 \%$ due to the increment of $2.1 \%$ demand for vegetables from the citizens starting of the year 2016 (DOA, 2016). Despite the increment on vegetable production, Malaysia still needs to import 1.49 million tons of vegetables to cater an inadequate demand in the country (DOA, 2019). Food production in Malaysia is still beyond the quantity required by Malaysian citizen. This is supported by the report from Ministry of International Trade and Industry that the demand for food is projected to increase more than $70 \%$ in 2050 due to the increment of the population in the city (MITI, 2015).

The Malaysian government has synthesized a strategic planning to increase vegetable production in the country. Instead of expanding agricultural land, vertical farming concept and urban farming are introduced to the urban communities in order to increase food production (DOA, 2016). Urban farming has been accepted in Malaysian and this activity is expected to increase food security among communities. Producing vegetables for the vertical farming requires seedling preparation in the nursery tray before it can be transferred to the pot.

Planting vegetable involves a few steps before it can be harvested. There are two methods of seeding; direct seeding and transplanting in the nursery tray. Direct seeding is a method of sowing seed in the field, while transplanting requires seed to be sown in the nursery tray. In nursery practice, germinated plant in the tray will be transferred into the field a few weeks after seeding. Sowing seed in the tray can solve the problem of seed wastage, especially when using an expensive hybrid seed compared to direct seeding (Space \& Balmer, 1977). Plants germinated in tray experience uniform crop development, efficient use of space and poses low risk of transplant injury due to the tray preserves healthy root form (Luna $e t$ $a l ., 2009)$. The main reason for the extra step of using nursery tray is to limit the amount of space initially required for germinating seeds. A lot of seedlings can be produced in a very small space using this method. It allows the farmer to select the strongest and most vigorous 
seedlings for use in transplants. Apart from all advantages of transplanting, seeding in the nursery tray requires extra work compared to the direct sowing. The farmer has to manually fill in the nursery tray with soil to prepare a medium for the seedling.

For transplanting activity, soil preparation in the nursery tray is the earliest process in planting vegetable. It is also one of the important stages, as it prepares the room for the seed to grow. Conventional activity on preparing media in nursery tray is the most inexpensive approach, but it is a labourious and time-consuming operation for high volume seeding (Pandiyaraj et al., 2017; Muthamil et al., 2015). It is largely operated by hand in Malaysia and contribute to higher number of workers and consume longer time compared to an operation conducted by a machine.

Manual soil-filling into the nursery tray is back breaking (Yeoh, 1988). This activity is not a good ergonomic practice for the human's body posture. In order to solve the problem that occurs in conventional seedlings production, soil-dispensing machine is developed with the local material available in the country to reduce the cost of the machine. A soil dispenser is developed to assists the farmer in sowing seed and to reduce the time to prepare the seedlings. A seed dispenser namely Tray Seeder which has been developed in MARDI is attached to this machine to complete the sowing process. The seed-dispenser is used to sow vegetables seeds into the nursery tray (Hafidha et al., 2020). The objective of this research is to evaluate the performance of the soil dispensing machine and to compare with traditional practice of soil filling into the nursery tray. The optimization of each parameter is also evaluated to obtain the exact volume of soil to filling the nursery tray. The effect of different hopper angle, speed of conveyor and auger to the volume of soil dispensed into the nursery tray using this machine are evaluated.

\section{Materials and Methods}

The machine performance assessment were conducted at Engineering Research Centre, in MARDI Serdang, Selangor. The machine used in this experiment was designed for releasing soil and seeds into a nursery tray. The test was conducted using peat moss from Holland. This research includes modification of the machine, testing, evaluation and analysis upon determination of the optimum parameters of the machine to achieve the target volume of soil dispensed into the nursery tray.

\subsection{Prototype of Soil-Dispensing Machine}

A soil-dispensing machine, as shown in Figure 1, consists of a conveyor, nursery tray holder, soil dispenser, scrapper, soil compactor, wiper motors, gears, microcontroller and sensors made up of different parts as per listed in Table 1. It was developed using locally materials available in the market. The structure of the machine was fabricated using mild steel and stainless steel at the less cost. Motors are used to move the conveyor and rotate the auger attached to the hopper. The main part of the soil-dispenser is a hopper which is a 
container used to store peat moss or soil (Prajakta et al., 2015). It is tapered downward to allow the soil to be dispensed with the help of an auger. The auger is actuated by a motor and controlled by a microcontroller.

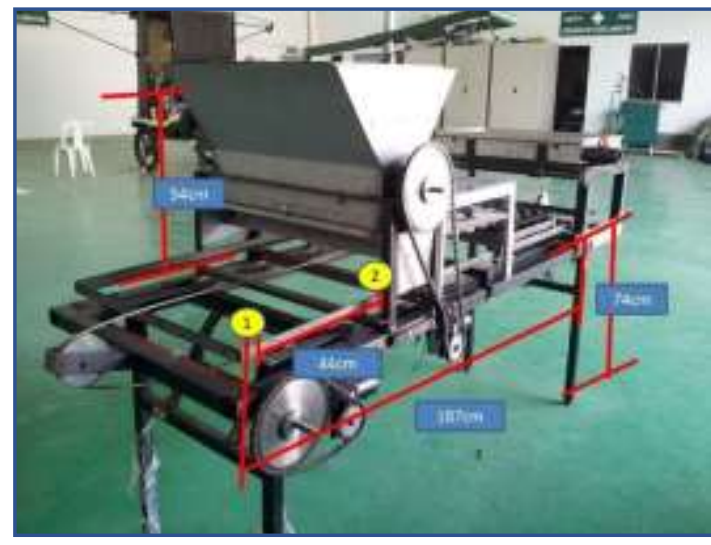

(a)

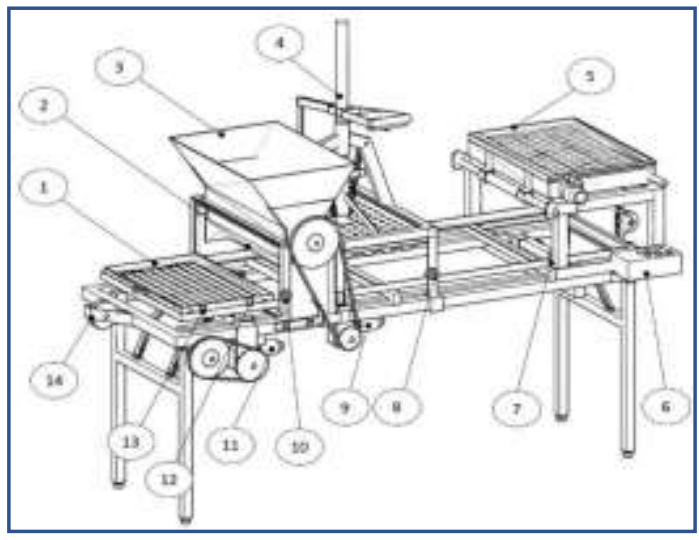

(b)

Figure 1. Soil dispensing machine: (a) Photographic view; (b) Isometric view.

Table 1. Parts of soil dispensing machine.

\begin{tabular}{ll}
\hline No & Part \\
\hline 1 & Conveyor \\
3 & Nursery tray holder \\
4 & Scrapper \\
5 & Soil dispenser / hopper \\
6 & Soil compactor \\
7 & Seed dispenser \\
8 & Microcontroller / main switch /push button PB3 \\
9 & Limit switch (S1) \\
10 & Distance sensor 2 (S2) \\
11 & Auger's motor \\
12 & Distance sensor 1 (S1) \\
13 & Conveyor's motor \\
14 & Magnet 1 (M1) \\
15 & Magnet 2 (M2) \\
\hline & Limit switch (S2) \\
\hline
\end{tabular}


The operation of the system is summarized in the flowchart in Figure 2. The operation began with putting the nursery tray on the nursery tray holder. There are two magnets attached to the tray holder for the distance sensors to detect the tray existence. The machine started by pushing the start button and the motor begin to actuate the conveyor. The conveyor moving forward to the soil-dispenser bringing the nursery tray to pass under the hopper. When the holder reached the dispenser, the auger motor started and allowing the soil to discharge from the hopper. The auger stops discharging soil when the holder passing the dispenser and move towards the soil-compactor. The conveyor stops when the distance sensor detected the arrival of the nursery tray, which has been positioned under the soilcompactor. The compactor compresses the soil in the nursery tray, making the depth of the current soil become more compact or about $3 / 4$ depth of nursery tray. This process is done manually by the operator. The conveyor starts moving, when the compactor is back to its original position. The nursery tray continues moving towards the seed-dispenser. The tray stops next to the seed-dispenser and the seed sowing begin to operate. The seeding process is done manually by the operator. Operator bring the plate attached with seeds facing to the nursery tray and switch-off the vacuum pressure to release the seed into the nursery tray.

After seeding completed, the operator needs to push the button and the conveyor motor rotates counterclockwise, bringing the tray holder back towards its original position. The nursery tray passes under the compactor and move towards the soil-dispenser. When the tray-holder reached the hopper, auger motor starts operating and soil discharges from the hopper into the nursery tray. The volume of soil discharged from the hopper is an amount needed to cover the seed on the compacted soil. The auger motor stopped discharging the soil, when the tray passed the hopper. The tray finally returned to its original position.

The soil-dispenser conducts two jobs as the machine operated. Firstly, the soil dispenser is used to fill soil into empty nursery tray. The full volume of soil is then being compressed by the compactor. Secondly, after seeds has been sowed on the compacted soil, the dispenser fills the nursery tray with soil to cover the seed. The scraper is used to flatten soil on top of the nursery tray. The conveyor is used to move the nursery tray from original position to soil dispenser and return to its original position. The soil dispensing machine was semi-automated and controlled by an Arduino microcontroller.

\subsection{Microcontroller and Sensors}

Arduino is chosen as a microcontroller for this prototype machine because it is reliable and cheap for prototype testing purposes (Daniel \& Peter, 2012). Arduino is preferable over the other microcontrollers because it is simple to code and it can be run in an open source platform (Parmenter et al., 2014). The controller is suitable for many types of sensor's integration (Louis, 2018). Distance sensors and limit switches are used on this machine to allow the operation of motors. 


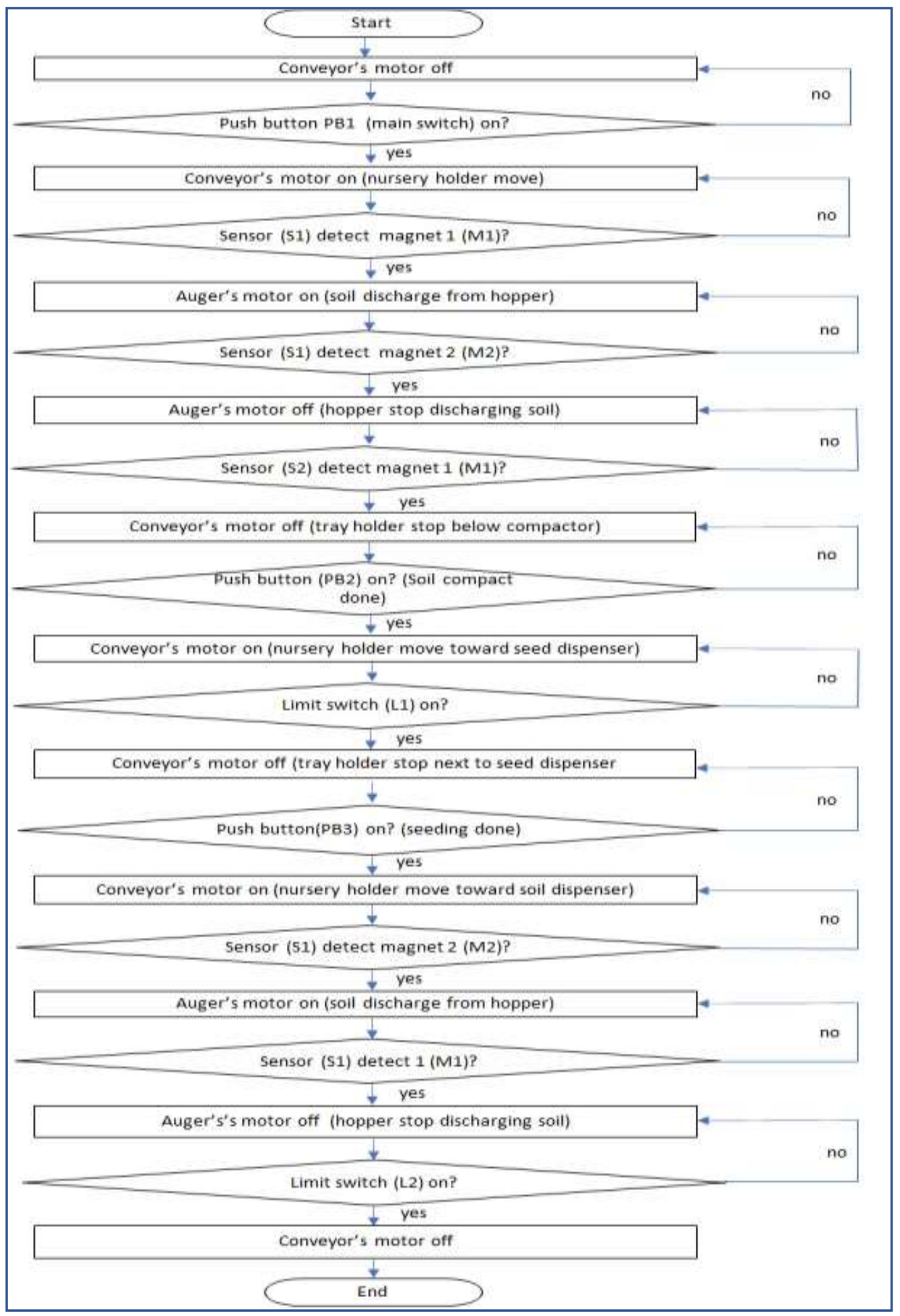

Figure 2. Flowchart of machine operation. 


\subsection{Test Procedure}

\subsubsection{Determination of properties of the nursery tray}

Three samples of nursery tray were selected from various types available in the market. The dimension of the hole and the size of the nursery tray were measured. The shape of a nursery tray hole is similar to the frustum of a cone, where the top portion of the cone has been cut off forming a lower base and an upper base that is circular and parallel. The volume of total holes on nursery tray is measured to calculate the volume of soil needs to dispensed. The volume of each hole was calculated using Equation 1 (Szirtes \& Rosza, 2007):

$$
\begin{aligned}
& \text { Volume of frustum of a cone }\left(\mathrm{cm}^{3}\right)= \\
& \frac{\pi\left(\text { Diameter }_{\text {big }}{ }^{2}\left(\mathrm{~cm}^{2}\right)+\text { Diameter }_{\text {small }}^{2}\left(\mathrm{~cm}^{2}\right)+\text { Diameter }_{\text {big }}(\mathrm{cm}) \times \operatorname{Diameter}_{\text {small }}(\mathrm{cm})\right)}{12}
\end{aligned}
$$

\subsubsection{Determination of the soil volume by varying hopper angle, speeds for conveyor motor} and auger motor

The speed of agricultural and food processing machinery often affects its performance (Jarimopas \& Rattanadat, 2007). The exact speed of the auger and the conveyor is important in order to discharge an accurate volume of soil. Therefore, it is essential to determine the best conveyor speed and rotating auger, which is actuated by motors. Each motor consists of two pieces of spur gears. The gears are used to increase rotational speed of the conveyor and the auger. The transmission power is conveyed by a roller chain. A good soil dispensing machine will be perceived by the farmer as a "perfection", when the soil dispensed into the whole nursery tray's cells can be filled to the fullest volume, without any spillage and wastage. The combination of two speeds results in an accurate timing for the nursery tray to reach at the position below the seed dispenser and the period of auger needed to dispense an exact volume of soil.

Arduino has its own motor driver. Thus, the speed of the motor is measured in 8-bit unit. The motor was controlled from the microchip and the speed can be changed by altering the algorithm. The 8 -bit represents value 0 to 255 , which 0 is the minimum speed and 255 is the maximum speed motor. The motor shall operate at the selected speed, between 0 to 255, when the input number is entered on Serial Monitor and processed via Arduino algorithm. The combination of two motor's speed in this experiment was monitored and the volume of soil dispensed from the hopper was measured. The value of 0 to 255 is referred to Pulse Width Modulation or known as PWM, where the output 0 is equal to $0 \%$ of duty cycle and 255 is equal to $100 \%$ of duty cycle. The speed of $3.5 \mathrm{~cm} / \mathrm{s}$ and $4.5 \mathrm{~cm} / \mathrm{s}$ were tested for auger capacity, while $19 \mathrm{~cm} / \mathrm{s}$ and $21 \mathrm{~cm} / \mathrm{s}$ were tested for conveyor capacity. 
Figure 3 shows the orientation of angle of the hopper. The angle $(\theta)$ is an important parameter affecting soil dispensing performance. Thus, $\theta$, is the angle between two perpendicular walls of the hopper. The machine has been developed with $45^{\circ}$ and $65^{\circ}$ angle of hopper. These angles were chosen based on manual fabricating of hopper in the fabrication workshop. Testing has been done with these two designs of hopper and the volume of soil dispensed from the hopper is observed at the end of the operation.

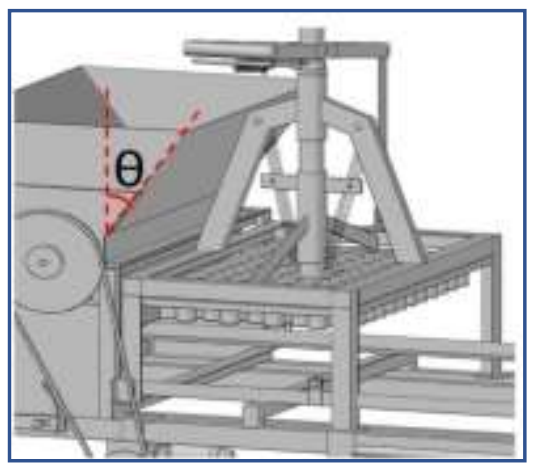

Figure 3. Hopper angle, $\theta$.

\subsubsection{Design optimization of the soil dispensing machine}

The optimum value for hopper angle, speed of conveyor and speed of auger were determined based on the result obtained earlier from the experiment. Three factors of two levels variance were selected in this experiment as shown in Table 2. The statistical analysis was performed by Design Expert software at significant of $95 \%$ level of confidence for variance $(p \leq 0.05)$.

The optimum values were determined twice. Firstly, optimum volume of soil dispensed is determined, when soil completely filled up the empty holes of nursery tray to the maximum, which is before soil is compacted. Secondly, the optimum volume of soil dispensed is needed to cover the whole seeds in the nursery tray, which occurs after soil is compacted.

Table 2. Factors and 2 level of variance in the experiment.

\begin{tabular}{cccc}
\hline Factor & Unit & Low level & High level \\
\hline Conveyor speed & $\mathrm{cm} / \mathrm{s}$ & 19 & 21 \\
Auger speed & $\mathrm{cm} / \mathrm{s}$ & 3.5 & 4.5 \\
Hopper angle & degree & 45 & 65 \\
\hline
\end{tabular}




\section{Results and discussions}

\subsection{Properties of the Nursery Tray}

Table 3 shows the volume of total holes calculated by using Equation 1. All types of nursery tray tested can be used with the soil-dispensing machine, since the dimension of the tray is suitable for design of the machine. However, the 104-type of nursery tray, composed of 104 holes, is widely used to germinate leafy vegetable due to its suitability volume of hole for root to grow. The target volume for soil to dispense from the hopper to fill the capacity of the nursery tray is $2873 \mathrm{~cm}^{3}$.

Table 3. Parameter of nursery tray.

\begin{tabular}{cc}
\hline Tray types (No of holes) & Volume of all holes, $\mathbf{V}\left(\mathbf{c m}^{\mathbf{3}}\right)$ \\
\hline 51 & 4870.856 \\
84 & 3745.905 \\
104 & 2873.099 \\
\hline
\end{tabular}

After the soil compacting step, the total volume of soil in the nursery reduces to 1693 $\mathrm{cm}^{3}$. The soil compactor compressed the height of the soil in the nursery tray from $4.0 \mathrm{~cm}$ to $3.2 \mathrm{~cm}$ and the diameter of top soil in the nursery tray from $3.7 \mathrm{~cm}$ to $1.8 \mathrm{~cm}$. The volume of soil needed to cover the seeds on top of the whole soils was $1180 \mathrm{~cm}^{3}$. This volume is calculated using formula of Equation 1.

\subsection{Determination of the Soil Volume by Varying Hopper Angle, Speeds for Conveyor Motor and Auger Motor}

Table 4 shows an experimental design and volume of soil dispensed from the hoper into the nursery tray. Result of the analysis of variance is shown in Table 5. From the statistical analysis, the model is significant with $p$-value $<0.0001$. Conveyor speed and auger speed were significant on the volume of soil dispensed from the hopper with a $p$-value $<0.0001$. Hopper angle shows significant effect on the response with $p$-value of 0.00112 . The combination of both speeds greatly affected the response with $p$-value $<0.0001$. Therefore, there is no interaction between the hopper angle, conveyor speed and auger speed.

Table 4. Volume of soil dispense from hopper.

\begin{tabular}{cccccc}
\hline Standard & Run & A: Conveyor speed & B: Auger speed & C: Hopper angle & Volume \\
\hline 1 & 6 & 19 & 3.5 & 45 & 2236 \\
2 & 1 & 19 & 3.5 & 45 & 2278 \\
3 & 24 & 19 & 3.5 & 45 & 2317 \\
4 & 23 & 21 & 3.5 & 45 & 1976 \\
5 & 11 & 21 & 3.5 & 45 & 1807 \\
6 & 16 & 21 & 3.5 & 45 & 1943 \\
7 & 17 & 19 & 4.5 & 45 & 2964 \\
\hline
\end{tabular}




\begin{tabular}{cccccc}
\hline Standard & Run & A: Conveyor speed & B: Auger speed & C: Hopper angle & Volume \\
\hline 8 & 22 & 19 & 4.5 & 45 & 2903 \\
9 & 10 & 19 & 4.5 & 45 & 2877 \\
10 & 18 & 21 & 4.5 & 45 & 1031 \\
11 & 2 & 21 & 4.5 & 45 & 1076 \\
12 & 7 & 21 & 4.5 & 45 & 998 \\
13 & 5 & 19 & 3.5 & 65 & 2369 \\
14 & 15 & 19 & 3.5 & 65 & 2412 \\
15 & 9 & 19 & 3.5 & 65 & 2343 \\
16 & 3 & 21 & 3.5 & 65 & 1998 \\
17 & 13 & 21 & 3.5 & 65 & 2016 \\
18 & 12 & 21 & 3.5 & 65 & 2061 \\
19 & 4 & 19 & 4.5 & 65 & 2986 \\
20 & 14 & 19 & 4.5 & 65 & 3007 \\
21 & 19 & 19 & 4.5 & 65 & 3096 \\
22 & 21 & 21 & 4.5 & 65 & 1003 \\
23 & 20 & 21 & 4.5 & 65 & 1032 \\
24 & 8 & 21 & 4.5 & 65 & 1079 \\
\hline
\end{tabular}

Table 5. Analysis of variance table.

\begin{tabular}{ccccccc}
\hline Source & & Sum of squares & DF & Mean Square & F Value & Prob $>$ F \\
\hline Model & & $1.179 \mathrm{E}=007$ & 4 & $2.947 \mathrm{E}+006$ & 1040.73 & $<0.0001$ \\
& $\mathrm{~A}$ & $7.898 \mathrm{E}+006$ & 1 & $7.898 \mathrm{E}+006$ & 2788.93 & $<0.0001$ \\
& $\mathrm{~B}$ & $1.210 \mathrm{E}+005$ & 1 & $1.210 \mathrm{E}+005$ & 42.72 & $<0.0001$ \\
& $\mathrm{C}$ & 41334.00 & 1 & 41334.00 & 14.60 & 0.00112 \\
& $\mathrm{AB}$ & $3.729 \mathrm{E}+006$ & 1 & $3.729 \mathrm{E}+006$ & 1316.67 & $<0.0001$ \\
Residual & & 53808.00 & 19 & 2832.00 & & \\
Lack of Fit & 13125.33 & 3 & 4375.11 & 1.72 & 0.2029 \\
Pure Error & & 40682.67 & 16 & 2542.67 & & \\
Cor Total & & 23 & & & \\
Std. Dev. & 53.22 & $1.184 \mathrm{E}+007$ & & Adj $R$-Squared & 0.9955 & \\
Mean & 2075.33 & & & Pred $R$-Squared & 0.9945 & \\
C.V & 2.56 & & Adeq Precision & 83.107 & \\
Press & 85854.32 & & &
\end{tabular}

Equation 2 indicates the final equation in terms of actual parameters that can be used to predict the soil volume.

$$
\text { Volume }\left(\mathrm{cm}^{3}\right)=1418.56293+3.87109 \mathbf{A}+11.05204 \mathbf{B}+4.15000 \mathbf{C}-0.080442 \mathrm{AB}
$$

Figure 4 shows the interaction graph of auger and conveyor speed. 
DESIGN-EXPERT Plot

volume

$X=A$ : Conveyor speed

$Y=B$ : Auger speed

- $8-3.500$

$\Delta+4.500$

Actual Factor

C: Hopper angle $=55.00$

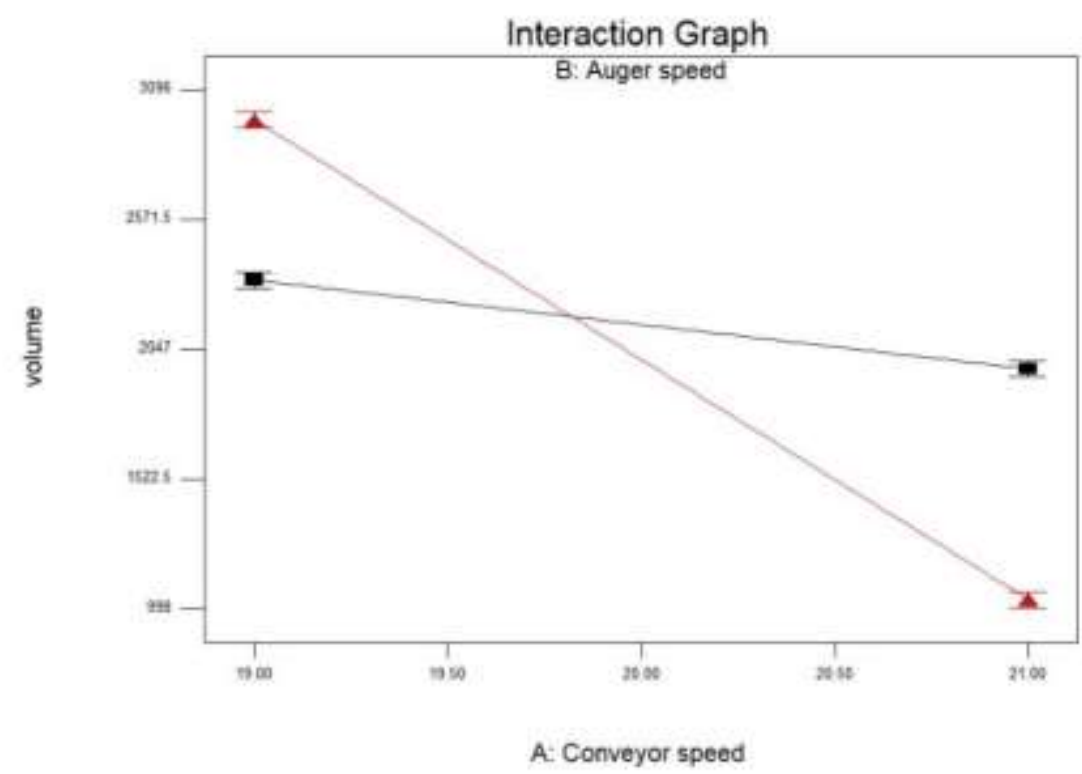

Figure 4. Interaction graph of auger and conveyor speed.

\subsection{Design Optimization of the Soil Dispensing Machine}

In order to achieve the target volume of soil to be dispensed by the hopper for the empty nursery tray, which is $2873 \mathrm{~cm}^{3}$, the operating conveyor speed, auger speed and angle of hopper should be set at $19.01 \mathrm{~cm} / \mathrm{s}, 4.30 \mathrm{~cm} / \mathrm{s}$ and $64.92^{\circ}$, respectively. The numerical optimization of the parameters with the response of desirability is shown as 3D surface graph in Figure 5. Machine modification is required to achieve the target of the output volume thus, the nearest solution of optimized parameter to set up the machine is $19.10 \mathrm{~cm} / \mathrm{s}, 4.5 \mathrm{~cm} / \mathrm{s}$ and $65^{\circ}$ for the conveyor speed, auger speed and angle of hopper, respectively. These tested parameters produced an output of $2912 \mathrm{~cm}^{3}$.

DESIGN-EXPERT PIOt

Desrability

$Y=B$ Auger speed

Actual Factor

C. Hopper angie $=6492$
$X=A$. Conveyor speed

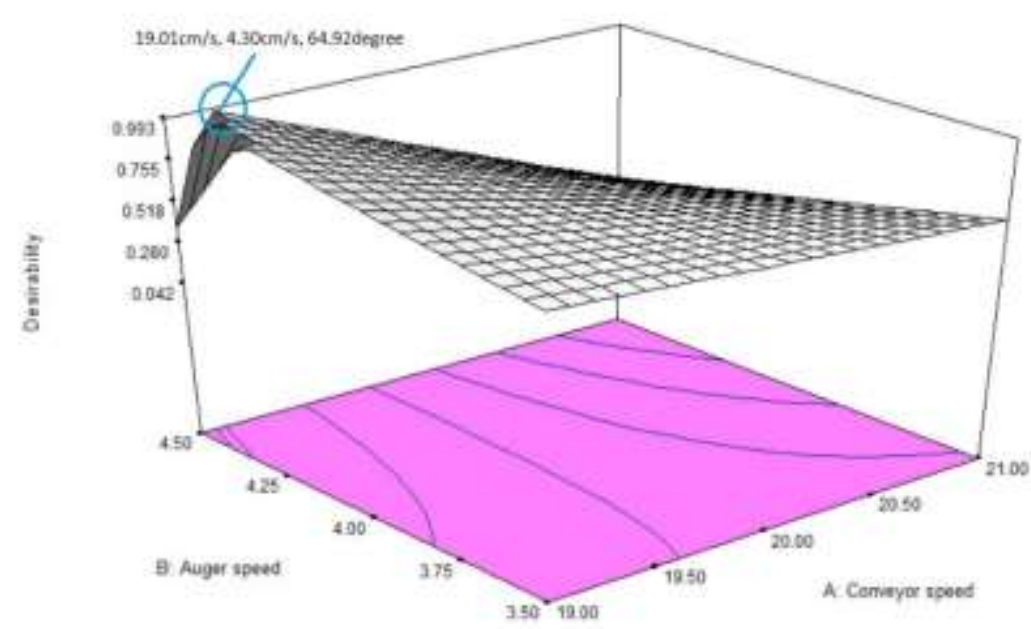

Figure 5. Surface graph shows the numerical optimization of the parameters for volume $2873 \mathrm{~cm}^{3}$. 
For the second times of soil dispensing operation, the volume of $1180 \mathrm{~cm}^{3}$ is required to cover the whole seeds in the nursery tray. The optimal value of the operating conveyor speed, auger speed and angle of hopper should be set at $20.96 \mathrm{~cm} / \mathrm{s}, 4.37 \mathrm{~cm} / \mathrm{s}$ and $51.77^{\circ}$, respectively, to achieve the volume of $1180 \mathrm{~cm}^{3}$ discharged soil. Figure 6 shows the surface graph of the numerical optimization for target volume of $1180 \mathrm{~cm}^{3}$. the nearest solution of optimized parameter to set up the machine is $21.0 \mathrm{~cm} / \mathrm{s}, 4.3 \mathrm{~cm} / \mathrm{s}$ and $50^{\circ}$ for the conveyor speed, auger speed and angle of hopper respectively. These tested parameters shall then produce an output of $1190 \mathrm{~cm}^{3}$.
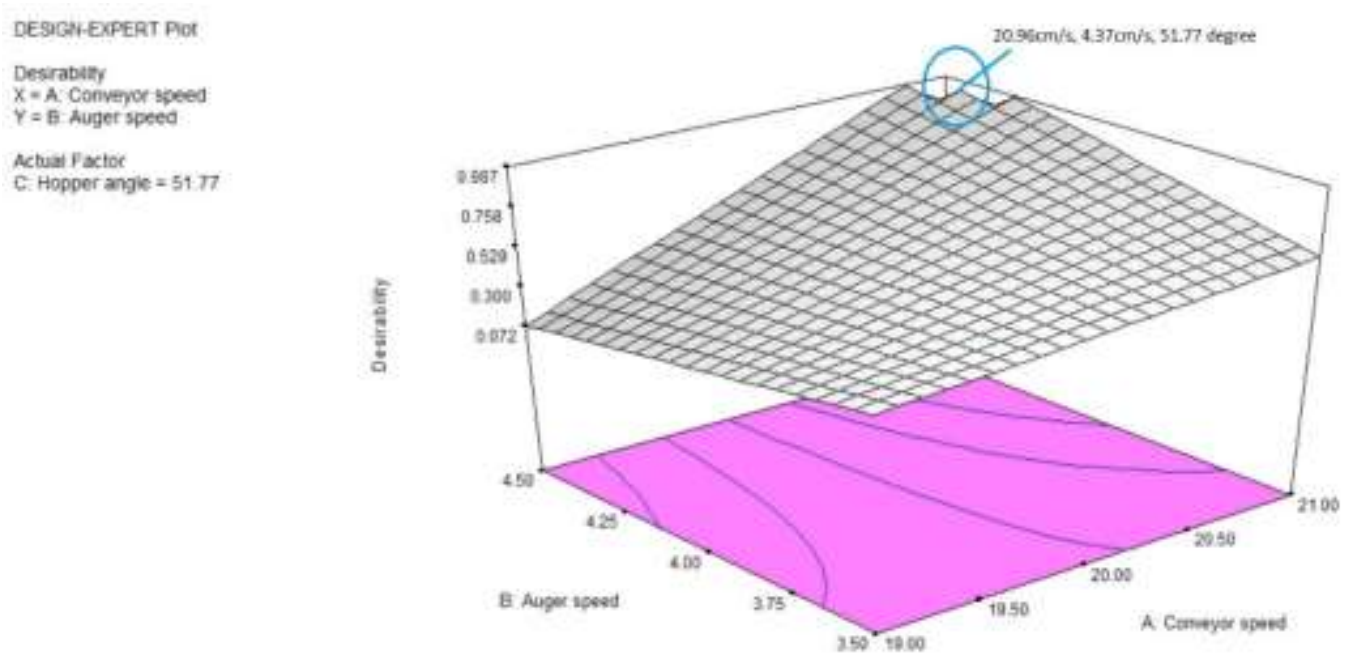

Figure 6. Surface graph shows the numerical optimization of the parameters for volume $1180 \mathrm{~cm}^{3}$.

From the optimization analysis, it can be concluded that to discharge $2912 \mathrm{~cm}^{3}$ of soil to fill the empty nursery tray requires lower conveyor speed, higher auger speed and hopper angle compared to discharge $1190 \mathrm{~cm}^{3}$ to cover the seed on the compacted soil. Reducing the conveyor speed allows longer time for the soil to discharge into the nursery tray, while increasing the auger speed allows, more volume of soil to discharge from the hopper. The angle of hopper also contributes to the volume of soil discharge. Thus, the bigger the angle, the highest the volume of soil could be dispensed.

\subsection{Performance of the Soil Dispensing Machine}

The performance of the machine is faster than manual activity on soil filling into the nursery tray. The continuous operation test indicated that the machine could achieve soil filling of nursery tray at an average time of 30 seconds and results in a complete process on seeding in one minute. Manual filling of the soil into the nursery tray took about three minutes to complete the cells and the whole seeding process took more than five minutes to complete the nursery tray.

The optimized soil-dispensing machine has alleviated the time consumption problem and trouble in filling soil and sowing small seeds into the continuous semi-automatic seeding 
system. The machine can provide high productivity and lower operating and labour cost compared to manual sowing operation.

\section{Conclusions}

The results clearly indicate that conveyor speed, auger speed and hopper angle can highly impact the volume of soil discharged from the soil-dispenser. The model is significant with $p$-value of $<0.0001$. Conveyor speed, auger speed and hopper angle were significant on the volume of soil dispensed with both speeds shows a $p$-value of $<0.0001$, while hopper angle shows $p$-value equal to 0.00112 . The combination of both speeds greatly affected the response with $p$-value $<0.0001$. There is no interaction between each speed and the hopper angle.

From optimization analysis, the operating conveyor speed, auger speed and angle of hopper should be set at $19.0 \mathrm{~cm} / \mathrm{s}, 4.5 \mathrm{~cm} / \mathrm{s}$ and $65^{\circ}$ to discharge $2912 \mathrm{~cm}^{3}$ soil. In order to cover seed of the compacted soil, $1190 \mathrm{~cm}^{3}$ soil is required, thus parameters should be set at $21 \mathrm{~cm} / \mathrm{s}, 4.3 \mathrm{~cm} / \mathrm{s}$ and $50^{\circ}$ with respect to conveyor speed, auger speed and hopper angle. The result shows that the machine can completely fill the nursery tray with soil and seed within one min per tray compared to manual process that took five min to complete the whole seeding process.

Conflicts of Interest: The authors declare no conflict of interest, and also the funders had no role in the design of the study; in the collection, analyses, or interpretation of data; in the writing of the manuscript, or in the decision to publish the results.

\section{References}

Daniel, K. F., \& Peter, J. G. (2012). Open-source hardware is a low-cost alternative for scientific instrumentation and research. Modern Instrumentation, 1, 8-20.

DOA. (2016). Pelan strategik jabatan pertanian 2016-2020. Retrieved on January 10, 2020 from http://www.doa.gov.my/index/resources/aktiviti_sumber/sumber_awam/penerbitan/pelan_strategik_doa_ 2016_2020.pdf

DOA. (2019). Booklet statistik tanaman 2019 (sub-sektor tanaman makanan), Jabatan Pertanian Malaysia. Retrived on December $\quad 15, \quad 2019 \quad$ from http://www.doa.gov.my/index/resources/aktiviti_sumber/sumber_awam/maklumat_pertanian/perangkaan_tanam an/booklet_statistik_tanaman_2019.pdf

Hafidha, A., Mohd Fazly, M., Mohd Taufik, A., et al. (2020). Performance evaluation of a seed dispenser for sowing seed into nursery tray. ASM Science Journal, 13(4), 27-35.

Jarimopas, B., \& Rattanadat, N. (2007). Development of a young coconut fruit trimming machine. Journal of Food Engineering, 79(3), 752-757. doi: https://doi.org/10.1016/j.jfoodeng.2006.01.082

Louis, L. (2018). Working principle of arduino and using it as a tool for study and research. International Journal of Control, Automation, Communication and Systems, 1(2), 21-29. doi: https://doi.org/10.5121/ijcacs.2016.1203 
Luna, T., Dumroese, W. K., \& Kasten, R. (2009). Seed Germination and Sowing Options; Nursery Manual for Native Plants: A Guide for Tribal Nurseries: Nursery management. Agriculture Handbook, U.S. Department of Agriculture. 1, 133-151

Muthamil, M. C. K., Thankamani, S. J. K., Annamalai, et al. (2015). Design and development of power-operated continuous-run potting machine for seedling-nursery. Indian Journal of Agricultural Sciences, 85(6), 817-820.

MITI (2015). Laporan Kementerian Perdagangan Antarabangsa dan Industri (MITI). Retrived on December 15, 2019 from http://www.miti.gov.my/miti/resources/MITI_Report_2015-5.pdf

Pandiyaraj, P., Kumar, Y. R., Vijayakumar, S., et al. (2017). Modern nursery raising systems in vegetables. International Journal of Agriculture Sciences, 9(52), 4889-4892

Parmenter, J., Jensen, A. N., \& Chiu, S. (2014). Smart irrigation controller. Electro/information technology (EIT), 2014 IEEE International Conference, 394-398. doi: https://doi.org/10.1109/EIT.2014.6871796

Prajakta, H., Nimish J., Pranav K., Amol, M.K. (2015). Automatic weighing and packaging machine. International Research Journal of Engineering and Technology, 6(5), 2129-2138. doi: https://doi.org/10.1016/j.isatra.2013.05.006

Space, J. C., \& Balmer, W. E. (1977). Minimum cost calculation for container planting. USDA Forest Service. South Eastern Area State and Private Forestry. Retrieved on March 12, 2020 from https://www.fs.fed.us/psw/publications/documents/psw_gtr200/psw_gtr200guide.pdf

Szirtes, T., \& Rozsa, P. (2007). Forms of Dimensionless Relations: Applied Dimensional Analysis and Modeling, Chapter 13 (2nd ed.). Elsevier Inc., 377

Yeoh, K. C. (1988). Mechanical transplanting of vegetable. Teknologi Sayur-Sayuran, 4, 33-38. 